\title{
Algorytm dekompozycji sieci transportowej
}

W pracy sformulowano zagadnienie wyboru optymalnej struktury sieci transportowej. Przedstawiono analize istniejacych metod optymalnej dekompozycji sieci. Zaproponowano przybliżony algorytm wyboru optymalnej struktury zarzqdzania sieciq transportowq oparty na analizie klasterowej $i$ klasyfikacji automatycznej.

\section{Wprowadzenie}

Z punktu widzenia teorii systemów, system transportowy należy traktować jako pewną organiczną całość składającą się ze struktur:

-podstawowych, obejmujących wszystkie obiekty jednorodne i istniejące pomiędzy nimi relacje oraz opisujące je cechy,

-głębokich, obejmujących procesy wraz $\mathrm{z}$ ich charakterystykami i utworzone przez nie struktury.

Zatem w analizie systemowej struktura odgrywa rolę kluczową. Znajomość struktur w systemach transportowych umożliwia analizę powiązań pomiędzy poszczególnymi podsystemami (i ich składowymi) oraz określa siłę oddziaływań pomiędzy nimi.

Podejście strukturalne może być skutecznie wykorzystane $\mathrm{w}$ wyborze optymalnej struktury zarządzania siecią transportową oraz $\mathrm{w}$ racjonalnym podziale funkcji pomiędzy poszczególnymi jego organami. Efektywne zarządzanie systemem wielkim i złożonym, a do takich należy system transportowy, związane jest ze strukturą hierarchiczna, pod którą rozumiana jest dekompozycja systemu na określoną liczbę podsystemów rzędu niższego, koordynowanych systemem rzędu wyższego. Zadanie koordynacji zarządzania podsystemami rzędu niższego jest tym łatwiejsze im bardziej są one autonomiczne i niezależne od siebie.

Zatem zadanie wyboru optymalnej struktury zarządzania w systemach transportowych sprowadza się do dekompozycji grafu sieci transportowej według przyjętego kryterium. Konieczność dekompozycji wynika ze złożoności problemów decyzyjnych, która rośnie w sposób wykładniczy wraz ze wzrostem rozmiarów sieci transportowej. W praktyce dekompozycja sieci zmniejsza ilość informacji przekazywanych na poziom wyższy, co w dużej mierze wpływa na efektywność zarządzania sieciami transportowymi.

$\mathrm{Z}$ matematycznego punktu widzenia przedstawiony problem można rozpatrywać $\mathrm{w}$ terminach teorii grafów.

Jak wiadomo, wartości miary podobieństwa pomiędzy elementami systemu są rozłożone nierównomiernie. $\mathrm{W}$ związku $\mathrm{z}$ powyższym $\mathrm{w}$ dowolnym systemie można wydzielić struktury elementów słabo ze sobą powiązanych, tj. rozdzielić system na podsystemy bliskich względem siebie elementów.
W niniejszej pracy przedstawiono dostatecznie prosty, w aspekcie obliczeniowym, algorytm strukturalizacji systemu przedstawionego grafem.

\section{Matematyczny model wyboru optymalnej struktury zarządzania}

Niech system obiektów zarządzania przedstawia graf niezorientowany $G(R, W)$, gdzie

$R=\left\{r_{1}, r_{2}, \ldots, r_{m}\right\}$ jest zbiorem obiektów traktowanych jako wierzchołki; $W=/ / w_{i j} / /$ jest wagą relacji pomiędzy $r_{\mathrm{i}}$ i $r_{j}, w_{i j} \geq o ; i_{i j}=1 ; m$ i $i \neq j$. Dla każdego podgrafu $G_{l}=G\left(R_{l}, W_{l}\right)$ odpowiadającego $l$-temu podsystemowi obiektów $R_{l}$ wybierzmy obiekt - przedstawiciel $r\left(R_{l}\right)$, przy czym:

$$
r\left(R_{l}\right) \in R_{l} ; R_{l} \subset R ; G_{l} \subset G
$$

Zadanie wyboru optymalnej struktury sprowadza się do podziału zbioru $\{\mathrm{R}\}$ na części $\left\{\mathrm{R}_{\mathrm{j}}\right\},\left(\left\{\mathrm{R}_{\mathrm{j}}\right\} €\right.$ $\{\mathrm{R}\}), j=\overline{1 ; k}$, gdzie $\mathrm{k}$ jest liczbą części o zadanych charakterystykach relacji. Biorąc pod uwage fakt, iż wzajemne relacje pomiędzy obiektami pierwotnymi rozłożone są nierównomiernie, zdanie wyboru racjonalnej struktury może być sformułowane jako zadanie dekompozycji grafu $G$ na $k$ części, która wyznacza ekstremum wybranego kryterium $C$. Strukturalizacja grafu $G$ odwzorowującego system transportowy jest zadaniem wielokryterialnym ze względu na fakt, iż graf ten przedstawia strukturę sieci transportowej, odnośnie której podejmowane jest wiele decyzji i rozwiązywane są różnorodne problemy dotyczące zarządzania. Można wydzielić następujące kryteria i ograniczenia dotyczące zadania dekompozycji grafu systemu transportowego $G$ :

1. Kryterium minimum sumy wag relacji pomiędzy częściami. Kryterium to zapewnia niezależność części, niezbędną do strukturalnego rozwiązywania problemów decyzyjnych. Wagę relacji pomiędzy obiektami pierwotnymi $i$ i $j$ można wyrazić następująco: 
a) $\quad w_{i j}=x_{i j}$, gdzie $x_{i j}$ - np. strumień wagonów próżnych przesuwanych od stacji $i$ do stacji $j$. Dekompozycja systemu według tego kryterium pozwala odrzucić niewygodne relacje przesuwu i tym samym zmniejszyć rozmiar rozpatrywanego zadania;

b) $w_{i j}=1 / r_{i j}$, gdzie $r_{i j}$ - odległość pomiędzy stacjami $i$ i $j$ mierzone $\mathrm{w} \mathrm{km}$;

c) $w_{i j}=1 / t_{i j}$, gdzie $t_{i j}$ - czas jazdy wagonów próżnych od stacji $i$ do stacji $j$;

d) $\quad w_{i j}=d_{i j}$, gdzie $d_{i j}$ - zdolność przepustowa szlaku ,stacja $i$ - stacja $j$ ”;

e) $w_{i j}=c_{i j}$, gdzie $c_{i j}$ - koszt przesuwu jednego wagonu próżnego pomiędzy stacjami $i$ i $j$.

Wagi relacji moga przyjmować również inne znaczenia, zależne od charakteru rozwiązywanego problemu.

2. Kryterium minimum liczby cykli pomiędzy częściami i maksimum liczby cykli wewnątrz części. Spełnienie tego kryterium, nawet $\mathrm{w}$ przypadku braku ograniczeń, w praktyce jest bardzo trudne. Tym nie mniej przy minimalizacji relacji zewnętrznych liczba cykli pomiędzy częściami również się zmniejsza.

3. Ograniczenie nałożone na średnicę l-tej części z góry:

$$
\sigma_{k}=\max _{i, j \in\left\{R_{L}\right\}} r\left(w_{i j} \leq \sigma^{*}\right), \quad \text { gdzie } \quad\left\{R_{L}\right\} \in\{R\},
$$

$r\left(w_{i j}\right)$ - droga od $i$ do $j$ - tego wierzchołka części $R_{l}$, określona jako najkrótsza droga od $i$ do $j$ [1].

4. Ograniczenia nałożone na sumę wag krawędzi w części, która powinna być ograniczona $\mathrm{z}$ dołu i z góry:

$W_{2} \leq \sum_{i, j \in\left\{R_{L}\right\}} w_{i j} \leq W_{1}$, gdzie $\left\{R_{L}\right\} \in\{R\}$.

5. Sumę wag obiektów w części $R_{l}$ również należy ograniczyć z dołu i z góry:

$P_{2} \leq \sum_{i \in\left\{R_{l}\right\}} p\left(r_{l}\right) \leq P_{1}$, gdzie $\left\{R_{l}\right\} \in\{R\}, p\left(r_{l}\right)-$ wa-

ga obiektu $r_{l}$.

Minimalizacja pierwszego i drugiego kryterium przy odpowiednich ograniczeniach jest złożonym zadaniem programowania dyskretnego, które obecnie nie posiada efektywnego algorytmu rozwiązywania. Jednym z podejść do rozwiązania zadania strukturalizacji jest więc wybór jednego kryterium, stosowanego do szerokiej klasy problemów decyzyjnych. W pracy [2] pokazano, że przy dostatecznie szerokich założeniach, zadanie wyboru racjonalnej struktury sprowadza się do minimalizacji sumy liczby relacji zewnętrznych pomiędzy częściami. Wszystkie relacje pomiędzy obiektami zadawane są $\mathrm{W}$ postaci macierzy kwadratowej $W=/ / w_{i j} / /$, przy czym $i_{i j}=\overline{1 ; m}$.

Sformułowanie matematyczne problemu optymalnej dekompozycji wyjściowego systemu transportowego sprowadza się do podziału (przekroju) zbioru wierzchołków grafu $G$ na $k$ podzbiorów, przy czym każdy z nich zawiera jeden $z$ wydzielonych $k$-wierzchołków. Przyjęty podział powinien minimalizować sumę wag krawędzi, których końce należą do różnych części przekroju lub maksymalizować sumę wag krawędzi wewnętrznych przekroju. Zauważmy, iż zadanie określenia minimalnego przekroju grafu pomiędzy wydzielonymi $k$-wierzchołkami, w przypadku $k=2$ sprowadza się do przypadku klasycznego, rozpatrywanego w teorii Forda - Fulkersona [3] i można go efektywnie rozwiązać stosując znany algorytm maksymalnego przepływu w sieci. Zatem rozpatrywane zadanie strukturalizacji sprowadza się do podziału grafu wyjściowego $G$ na $k$ rozłącznych podgrafów $G_{l}, G_{2}, \ldots, G_{k}$ w taki sposób, aby suma wag relacji pomiędzy podgrafami była minimalna, $\mathrm{tj}$.:

$$
C=C\left(R_{1}, R_{2}, \ldots, R_{k}\right)=\frac{1}{2} \sum_{i=1}^{k} \sum_{i_{i} \in R_{i} r_{j} \in R_{j}} w_{i j} \rightarrow \min
$$

i został spelniony warunek:

$$
R=\bigcup_{l=1}^{k} R_{L} ; R_{l} \bigcap R_{p}=\phi \quad l, p=\overline{1, k} ; l \neq p ; \exists r\left(R_{l}\right)
$$

\section{Analiza istniejących metod wyboru optymalnej struktury zarządzania}

Obecnie istnieje wiele algorytmów dotyczących dekompozycji sieci. Rozważane zadanie minimalizacji (1) może być sformułowane w języku programowania całkowitoliczbowego [4,5]. Przyjmuje się, że liczba elementów w podziałach $R_{j}$ jest ograniczona liczbą $d$. Wprowadza się macierz $\mathrm{X}=/ / \mathrm{x}_{\mathrm{ij}} / /$ o wymiarze $n x d$, gdzie $n-$ jest liczbą podziałów. Elementy macierzy są równe:

$$
x_{i j}=\left\{\begin{array}{l}
1, \text { for } \rightarrow r_{i} \in R_{L} \\
0, \text { for } \rightarrow r_{j} \notin R_{L}
\end{array}\right.
$$

Wiadomo, że:

$$
\begin{aligned}
& \sum_{i} x_{i j}=1 \\
& \sum_{j} x_{i j} \leq d
\end{aligned}
$$

W pracy [6] pokazano, że sformułowane zadanie sprowadza się do zadania kwadratowego programowania całkowitoliczbowego:

$$
\max 0,5 \sum_{q=1}^{n} \sum_{p=1}^{m} \sum_{j=1}^{m} w_{p j} x_{q j} x_{q p}
$$

Obecnie nie istnieją efektywne metody rozwiązywania podobnych zadań, dlatego proponuje się linearyzację wyrażenia (3). Model liniowy może być przedstawiony 
po wprowadzeniu dodatkowych zmiennych $y_{q p j}=x_{q j}$ $x_{q p}$ o liczbie $n m^{2}$.

Zadanie liniowe całkowitoliczbowe ma postać:

$$
\max \sum_{q=1}^{n} \sum_{p=1}^{m} \sum_{j=1}^{m} w_{p j} y_{q p j}
$$

przy ograniczeniach:

$$
\left\{\begin{array}{l}
\sum_{q=1}^{m} \sum_{j=1}^{m} y_{q p j}=m^{2} \\
x_{q i}+x_{q p}-2 y_{q p j} \geq 0 \\
1 \geq x_{j} \geq 0 \\
1 \geq y_{q p j} \geq 0
\end{array}\right.
$$

Zadanie (4) można rozwiązać stosując metodę podziału i ograniczeń. Algorytm ten nie uwzględnia specyfiki rozwiązywanego zadania, wymaga dużej liczby iteracji, jest złożony w sensie języka programowania i fizycznej interpretacji procesu minimalizacji. Wykorzystując dany algorytm należy określić ograniczenie dotyczące liczby obiektów w podziale.

W pracy [7] rozpatrywane jest zadanie podziału systemu przedstawionego grafem na zadaną liczbę jednakowych grup, zawierających najmniejszą liczbę relacji. Algorytm podziału grafu na minimalne spójne podgrafy, oparty na idei metody podziału i ograniczeń przedstawiono w pracy [8]. W pracy [9] rozważono dekompozycję systemu na podsystemy, liczby których nie zadano. W kryterium podziału uwzględnia się złożoność wydzielonych podsystemów i stopień ich spójności. Jakość podziału ocenia się według siły spójności i złożoności otrzymywanych podsystemów. W poszukiwaniu podziału optymalnego wykorzystuje się również algorytm przeglądu ograniczonego [10]. Istnieją także inne algorytmy dekompozycji [2], lecz nie uwzględniają one specyfiki zadania (1), są złożone w sensie obliczeniowym i fizycznej interpretacji procesu minimalizacji. Algorytmy te nie uwzględniają również faktu, że podstawowym kryterium dekompozycji grafu powinno być rozwiązanie bliskie rozwiązaniu optymalnemu.

W niniejszej pracy przedstawiony jest przybliżony algorytm rozwiązania zadania dekompozycji (1), pozbawiony wyżej wymienionych wad, oparty na analizie klasterowej [11, 12] i klasyfikacji automatycznej [13].

\section{Algorytm klasyfikacji automatycznej}

Podstawą wykorzystywanych metod analizy klasterowej i klasyfikacji automatycznej jest fundamentalna dla nauki zasada klasyfikacji oparta na twierdzeniu, że dowolne fakty i zjawiska powinny być sklasyfikowane $\mathrm{tj}$. uporządkowane lub pogrupowane zanim zostaną opracowane ogólne zasady objaśniające ich pojawienie się i wzajemne powiązania. A więc klasyfikacja jest uporządkowaniem i grupowaniem obiektów według cech podobieństwa. Przy czym, pod pojęciem obiektów można rozumieć również procesy i działania.

Rozważmy dane zadanie w sposób formalny. Niech stany obiektów badanych (dróg, stacji, itp.) będą opisane wektorem deskryptorów lub wielowymiarowym zbiorem cech

$X=\left\{X^{l}, X^{2}, \ldots, X^{n}\right\}$. Część z tych cech ma charakter ilościowy i może przyjmować dowolne wartości rzeczywiste. Pozostałe cechy mają charakter jakościowy i pozwalaja grupować obiekty według stopnia pojawiania się dowolnej jakości (np. cecha binarna odwzorowuje istnienie lub brak danej właściwości).

Wprowadźmy do rozważań przestrzeń parametrów $X$, w której każdemu konkretnemu obiektowi $X_{i}=\left\{X^{l}, X^{2}\right.$, $\left.\ldots, X^{n}\right\}$ odpowiada punkt $X_{i} \in X$. Załóżmy, że posiadamy kilka różnych klas takich obiektów. Jeśli położenie punktów w $X$ jest takie, iż poszczególnym klasom odpowiadają dostatecznie izolowane od siebie grupy punktów, to zadanie wydzielenia takich grup punktów jest zadaniem klasyfikacji $[11,12]$.

Bliskość pomiędzy elementami zbioru abstrakcyjnego związana jest z pewną topologią. Tym samym przestrzeń opisująca $X$ przekształca się w przestrzeń topologiczna. Dla określenia funkcji celu należy wprowadzić charakterystykę, która określi stopień podobieństwa danej klasyfikacji z wprowadzoną topologią. Charakterystykę tę czasami nazywa się miarą zagęszczenia lub kryterium grupowania.

Istnieje wiele sposobów określania topologii w przestrzeni opisów. Jednym z nich jest wyrażenie topologii poprzez miarę podobieństwa. Dowolna miara podobieństwa jest funkcją zależności każdej pary punktów $X_{i}, X_{j}$ ze zbioru $X$ od liczby $p\left(X_{i}, X_{j}\right)$.

Ogólne wymagania stawiane miarom podobieństwa są następujące:

1) powinny być wielkością dodatnią, tj.

$$
p\left(X_{i}, X_{j}\right) \geq 0
$$

2) powinny być symetryczne, tj.

$$
p\left(X_{i}, X_{j}\right)=p\left(X_{j}, X_{i}\right)
$$

3) miara podobieństwa obiektu do siebie jest maksymalna:

$$
p\left(X_{i}, X_{j}\right) \geq p\left(X_{i}, X_{j}\right), i \neq j
$$

4) $p\left(X_{i}, X_{j}\right)=0$ wtedy i tylko wtedy, gdy $X_{i}=X_{j}$

5) $\quad p\left(X_{i}, X_{j}\right) \leq p\left(X_{i}, X_{k}\right)+p\left(X_{k}, X_{j}\right), \quad$ gdzie $X_{i}, X_{j}, X_{k}$ - obiekty dowolne

Miarą podobieństwa może być współczynnik korelacji i odległość w przestrzeni metrycznej.

Najczęściej wykorzystuje się metrykę euklidesową, związaną z intuicyjnym szacowaniem odległości jako miary podobieństwa pomiędzy obiektami, wyrażoną wzorem:

$$
p_{e}\left(X_{i} X_{j}\right)=\left[\sum_{k=1}^{n}\left(X_{i}^{k}-X_{j}^{k}\right)^{2}\right]^{\frac{1}{2}}
$$


Miarę podobieństwa dwóch punktów $X_{i}$ i $X_{j}$ może być również funkcja potencjalna $K\left(X_{i} X_{j}\right)$ wyrażająca odległość pomiędzy tymi punktami [14].

Zazwyczaj funkcja ta ma następujące wyrażenie:

$$
K\left(X_{i}, X_{j}\right)=\frac{1}{1+\alpha p^{2}\left(X_{i}, X_{j}\right)}
$$

gdzie $\alpha$ - jest parametrem.

Obiekty $X_{i}$ i $X_{j}$ można odnieść do jednej klasy, jeżeli miara podobieństwa pomiędzy nimi będzie dostatecznie mała.

W niniejszej pracy przedstawiono algorytm klasyfikacji oparty na budowie minimalnego szkieletowego drzewa.

Niech wyniki pomiarów $p$ obiektów przedstawia macierz o wymiarze $n x p$ :

$$
\left.\begin{array}{c}
X_{1} \\
X_{2} \\
\vdots \\
X_{p}
\end{array}\right\} \rightarrow\left|\begin{array}{c}
X_{1}^{1} X_{1}^{2} \ldots X_{1}^{n} \\
X_{2}^{1} X_{2}^{2} \ldots X_{2}^{n} \\
\ldots \ldots \ldots \ldots \ldots . . \\
X_{p}^{1} X_{p}^{2} \ldots X_{p}^{n}
\end{array}\right|
$$

Wtedy odległość pomiędzy parami obiektów można przedstawić w postaci macierzy kwadratowej o postaci:

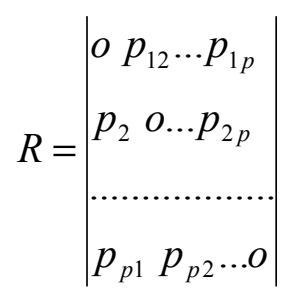

przy czym $p_{i i}=0 ; i=\overline{1 ; p}$.

Algorytm klasyfikacji zawiera dwa kroki podstawowe: Krok 1. Budowa minimalnego szkieletowego drzewa $\mathrm{z}$ wykorzystaniem macierzy $R$.

Niech $\left\{r_{1}, r_{2}, \ldots, r_{p-1}\right\}$ oznacza zbiór wag (długości) krawędzi minimalnego szkieletowego drzewa.

Krok 2. Wierzchołki minimalnego szkieletowego drzewa grupuje się w klasy. Wybiera się dwa obiekty, którym odpowiada krawędź minimalna i grupuje się je do jednej klasy, po czym procedurę kroku 2 powtarza się.

Na rys. 1 przedstawiono minimalne szkieletowe drzewo zbudowane z 8 obiektów z zadanymi wagami krawędzi. Proces grupowania obiektów w liczby pokazano na rys. $2 \mathrm{w}$ formie drzewa.

Przy zmniejszaniu miary podobieństwa $p$ drzewo stopniowo rozpada się, początkowo na dwa poddrzewa, potem na trzy, cztery, itd., co odpowiada dwóm, trzem, czterem, itd. klasom.

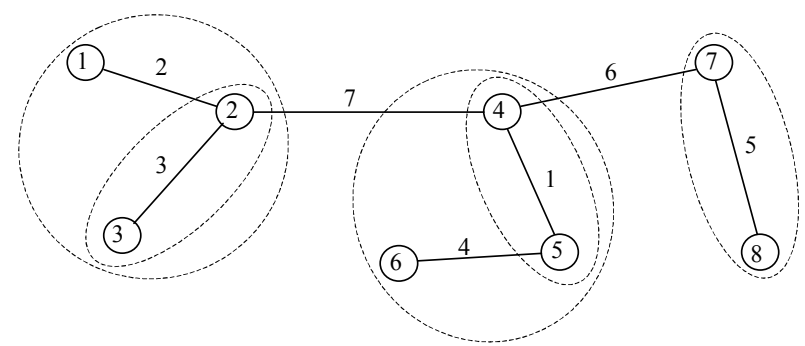

Rys. 1. Minimalne szkieletowe drzewo

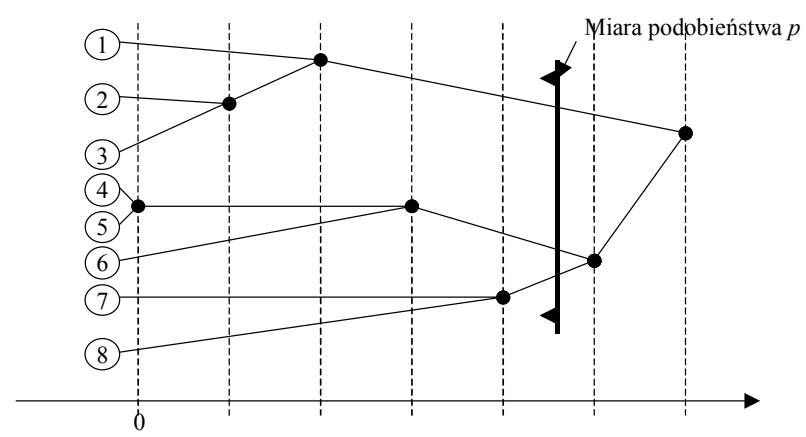

Rys. 2. Proces grupowania obiektów w klasy

Opracowany algorytm, oparty na skojarzeniach heurystycznych, można wykorzystać do wstępnego podziału, np. sieci dróg kolejowych na okręgi lub rejony w taki sposób, aby w jeden spójny rejon weszły te stacje i te odcinki dróg, pomiędzy którymi przewozi się najwięcej towarów i/lub pasażerów.

\section{Wnioski}

1. Efektywne podejmowanie decyzji w systemach transportowych wymaga hierarchicznej struktury zarządzania, w której podsystemy niższego rzędu koordynowane są podsystemowi rzędu wyższego. Koordynacja jest tym łatwiejsza im bardziej autonomiczne $\mathrm{i}$ niezależne od siebie są podsystemy rzędu niższego.

2. Zadanie wyboru optymalnej struktury zarządzania systemami transportowymi jest zadaniem dekompozycji według dowolnego kryterium. Konieczność dekompozycji wynika $\mathrm{z}$ dużych rozmiarów i złożoności rozwiązywanych problemów decyzyjnych. Dekompozycja pozwala na zmniejszenie ilości informacji przekazywanej na poziom wyższy.

3. Sformułowany problem może dotyczyć nie tylko systemów transportowych, ale również pozatransportowych, w których elementy są w dowolny sposób ze sobą powiązane. Wartości miary podobieństwa rozłożone są pomiędzy elementami nierównomiernie. $\mathrm{Z}$ tego wynika, że $\mathrm{w}$ systemie można wydzielić strukturę słabo powiązanych pomiędzy sobą grup obiektów, tj. podzielić system na podsystemy względnie bliskich obiektów. 
4. Jedynym sformułowaniem matematycznym zadania dekompozycji jest podział zbioru wierzchołków grafu, odwzorowującego strukturę sieci transportowej na $k$ nie przecinających się podgrafów, przy czym każdy z nich zawiera jeden z wydzielonych $k$ - wierzchołków (obiektów - przedstawicieli). Optymalna dekompozycja sieci transportowej jest zadaniem wielokryterialnym ze względu na złożoność problemów decyzyjnych w systemach transportowych.

5. Jednym z podejść prowadzących do rozwiązania zadania strukturalizacji systemu transportowego jest wybór jednego kryterium podziału. Zadanie wyboru racjonalnej struktury sieci transportowej prowadzi do minimalizacji sumy relacji zewnętrznych pomiędzy $k$ - podsystemami lub maksymalizacji sumy relacji wewnętrznych, pomiędzy $k$ podsystemami.

6. Analiza istniejących algorytmów rozwiązujących zadanie dekompozycji sieci według kryterium minimalizacji sumy liczby relacji zewnętrznych pokazała, że są one pracochłonne i skomplikowane w aspekcie programowania. W niniejszej pracy zaproponowano algorytm przybliżony, pozbawiony tych wad, oparty na analizie klasterowej i klasyfikacji automatycznej.

7. Opracowany algorytm klasyfikacji automatycznej bazuje na budowie minimalnego szkieletowego drzewa i może być wykorzystany do wstępnej dekompozycji systemów zarówno transportowych jak i pozatransportowych.

\section{Literatura}

[1] Minieka E., Maximal Lexicographic, and Dynamic Network Flows, "Operations Research", 1973,vol.20, s. 517-527

[2] Цвиркун А. Д. Структура сложных систем. M, «Сов. Радио», 1975

[3] Ford L.R., Fulkerson D.R., Przeptywy $w$ sieciach, PWN, Warszawa 1969

[4] Hu T., Integer Programming and Network Flows, Addison-Wesley, 1969

[5] Кристофидес Н., Теория графов: алгоритмический подход. М.,»Мир», 1978

[6] Nieminen J., On minimum point cutsetsof a point weightet communication graph, Control and $C y$ bernetics, vol. 3(1974) $N$ 3/4, p. 90-92

[7] Орлова Г. И.,Дорфман Я.Г.,Оптимальное деление графа на несколько подграфов, Техническая кибернетика, 1972,№ 1,c.118-121

[8] Рыжков А. П., Алгоритм разбиеня графа на минимально связанные подграфы. Техническая кибернетика, 1975,№ 6,c.122-128

[9] Моисенко Г.Е., Оптимальное разбиение системь на подсистемы, Автоматика и телемеханика, 1979 , №7, с.103-112

[10] Кнут Д., Искусство программирования на ЭВМ: Основы программированя, т.1, М., »Мир», 1976

[11] Дюран Б.,Оделл П.,Кластерный анализ,М., «Статистика», 1977

[12] Жамбю М., Иеархический кластер-анализ и соответствия, М.,Финансы и статистика», 1988

[13] Классификация и кластер, под редакиией Д.Вэна, М.,»Мир», 1980

[14] Айзерман М. А., Браверман Э. М., Розоноэр Л.И. , Метод потенциальных функиии и теория обучения машин, М.,»Наука», 1988 